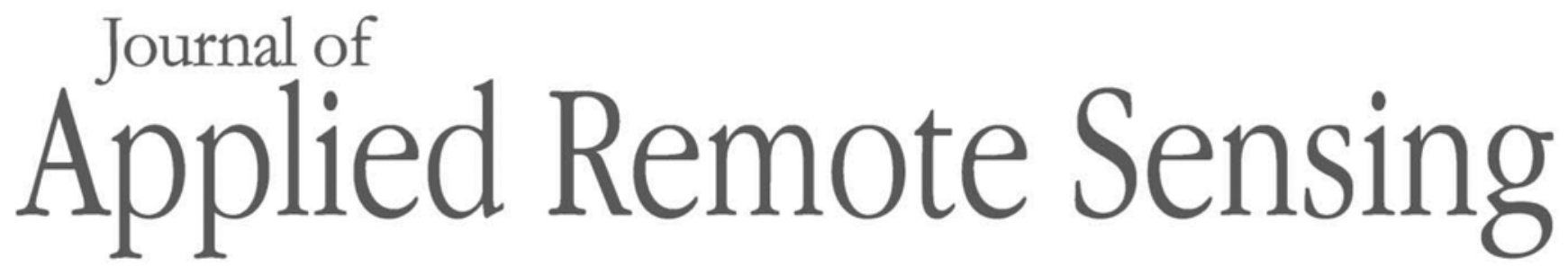

RemoteSensing.SPIEDigitalLibrary.org

\title{
Detecting and mapping Gonipterus scutellatus induced vegetation defoliation using WorldView-2 pan-sharpened image texture combinations and an artificial neural network
}

Romano Lottering

Onisimo Mutanga

Kabir Peerbhay

Riyad Ismail 


\title{
Detecting and mapping Gonipterus scutellatus induced vegetation defoliation using WorldView-2 pan-sharpened image texture combinations and an artificial neural network
}

\author{
Romano Lottering,* Onisimo Mutanga, Kabir Peerbhay, and Riyad Ismail \\ University of KwaZulu-Natal, School of Agricultural, Earth and Environmental Sciences, \\ Discipline of Geography, Pietermaritzburg, South Africa
}

\begin{abstract}
Defoliation induced by the weevil Gonipterus scutellatus is causing significant damage to South Africa's eucalyptus plantations. Therefore, the ability of remote sensing to detect and map G. scutellatus defoliation is essential for monitoring the spread of the weevil so that precautionary measures are set in place. In our study, an integrated approach using image texture in various processing combinations and an artificial neural network (ANN) were developed to detect and map G. scutellatus induced vegetation defoliation. A $0.5-\mathrm{m}$ WorldView-2 pansharpened image was used to compute texture parameters from the gray-level occurrence matrix and gray-level co-occurrence matrix, using optimal moving windows for specific levels of G. scutellatus induced vegetation defoliation. In order to improve the accuracy of detecting and mapping G. scutellatus induced vegetation defoliation, a method involving a three-band texture processing combination was proposed and tested. Using a sequential forward selection algorithm allowed for the selection of optimal texture combinations, which were subsequently input into a backpropagation ANN. The results showed an improvement in detecting vegetation defoliation using single texture bands $\left[R^{2}=0.82\right.$, root mean square error (RMSE) $=0.95$ (1.82\% of the mean measured defoliation)] when compared to single spectral reflectance bands $\left[R^{2}=0.60, \operatorname{RMSE}=1.79(3.43 \%\right.$ of the mean measured defoliation) $]$, two-band spectral reflectance combination model $\left[R^{2}=0.74, \mathrm{RMSE}=1.48(2.83 \%\right.$ of the mean measured defoliation)], and the three-band spectral reflectance combination model $\left[R^{2}=0.80, \mathrm{RMSE}=1.35\right.$ (2.59\% of the mean measured defoliation)]. Further improvements were obtained using the two-band texture combination model $\left[R^{2}=0.85\right.$, RMSE $=1.05(2.01 \%$ of the mean measured defoliation)] and the most promising result was obtained using the proposed three-band texture combination model $\left[R^{2}=0.90, \operatorname{RMSE}=0.85(1.63 \%\right.$ of the mean measured defoliation) $]$. Overall, our study highlights the potential of image texture combinations in improving the detection and mapping of vegetation defoliation. (c) 2019 Society of Photo-Optical Instrumentation Engineers (SPIE) [DOI: 10.1117/1.JRS.13.014513]
\end{abstract}

Keywords: Gonipterus scutellatus; defoliation; image texture; artificial neural network.

Paper 180582 received Aug. 7, 2018; accepted for publication Jan. 15, 2019; published online Feb. 8, 2019.

\section{Introduction}

In South Africa, eucalyptus plantations cover $\sim 700,000$ ha of the country's land base and is considered one of the most productive commercially planted exotic species in the country. ${ }^{1}$ However, the sustainability of these prolific species is threatened by outbreaks of the weevil Gonipterus scutellatus Gyllenhal (Coleoptera: Curculionidae). ${ }^{2,3}$ The weevil is native to south-east Australia and has subsequently perpetuated across the globe, with first reports of establishment in South Africa in 1916..$^{3-5}$ The weevil is a specialist on the genus Eucalyptus and is considered an important limiting factor, which may cause a significant loss of productivity in established eucalyptus plantations. ${ }^{4,6}$ The effects of repeated aggressive feeding by the weevil may result in a reduction in eucalyptus growth rates and subsequent tree mortality. ${ }^{7}$ The problem

*Address all correspondence to Romano Lottering, E-mail: lottering@ukzn.ac.za

$1931-3195 / 2019 / \$ 25.00$ (C) 2019 SPIE 
is further augmented as many eucalypts demonstrate little to no resistance to the weevil, which is of major apprehension to South Africa's commercial forestry sector. ${ }^{3}$ Primary management strategies to control weevil population densities may include either planting of nonsusceptible species of eucalyptus ${ }^{3,8}$ or the use of biological control. ${ }^{4,9}$ The latter was initiated in 1926 when the egg parasitic wasp Anaphes nitens Siscaro (Hymenoptera: Mymaridae) was first introduced into South Africa. ${ }^{4,10}$ However, South Africa's environmental conditions and the absence of environmental resistance provide favorable conditions for the weevil to proliferate. ${ }^{11,12}$

Therefore, measures need to be set in place for incipient detection and monitoring of weevilinduced vegetation defoliation, as to ensure that appropriate interventions are set in place before a point of nonrecovery is reached. Although conventional methods of monitoring vegetation defoliation are widely used, in this regard, they may be expensive, subjective, time consuming, and spatially restrictive. ${ }^{13-16}$ On the contrary, remote sensing offers a synoptic view of phenomenon on the ground, therefore having the potential to adequately detect and map vegetation defoliation induced by insects and other defoliating agents. ${ }^{14,15,17}$ The basis for monitoring and assessing forest health using remote sensing can be achieved by either detecting subtle spectral changes of foliage ${ }^{13}$ or foliage reduction. ${ }^{18,19}$ Previous studies have used vegetation indices to provide a quantitative framework for detecting and monitoring vegetation defoliation. ${ }^{18,20,21}$ For example, Lottering et al. ${ }^{19}$ used spatially optimized vegetation indices and successfully detected and mapped vegetation defoliation and leaf area index. However, since defoliation is expressed in tree crowns and canopies, some studies have argued that when using high spatial resolution data, image texture would be a more significant source of information. ${ }^{22,23}$

Image texture is used to determine the spatial orientation of features within high spatial resolution imagery. ${ }^{24-26}$ It is a function of local variance and is thus scale dependent. ${ }^{22,27}$ This method captures the spatial information composed within a remotely sensed scene, making it possible to identify aspects of forest structure, which may include vegetation defoliation. ${ }^{28,29}$ Yuan et al., ${ }^{30}$ for instance, used image texture to detect sugar maple decline and found that changes in tree crowns due to shoot dieback resulted in changes in image texture and could be quantified using linear models. Similarly, Moskal and Franklin ${ }^{22}$ used image texture analysis computed from high spatial resolution CASI image data and successfully detected the severity of aspen defoliation. The current study extends the work of previous studies ${ }^{22,30}$ by exploring the capability of image texture combinations in improving the detection of pest induced vegetation defoliation. Therefore, a three-band image texture processing combination approach was developed and tested in this study. The premise of this approach is twofold: (1) image texture has the capability of improving the detection of vegetation defoliation by simplifying the structure of the canopy and (2) band combinations have previously shown to improve the detection of vegetation defoliation when compared to the utility of individual bands. This is achieved by reducing background effects, sun angle effects, sensor angle effects, and atmospheric effects. ${ }^{31,32}$ In essence, the three-band image texture processing combination proposed in this study combines these two unique techniques, thus aiming to improve the detection of vegetation defoliation. In addition, previous studies have also focused on the relationship between image texture and defoliation using linear regression models, which assumes that a linear relationship exists between phenomena.

However, this is not always the case, as phenomena may be more complex and follow a nonlinear relationship, which can be effectively investigated using multivariate regression techniques. For example, an artificial neural network (ANN) is a multivariate regression technique that does not make any assumptions about the data. ${ }^{33}$ This algorithm emulates the functionality of the biological nervous system, demonstrating predictive capabilities that are not found in traditional statistical techniques. ${ }^{24,33,34}$ Many studies support the utility of an ANN in understanding complex relationships, as it has the capacity to deal with non-normality, nonlinearity, and collinearity within a system. ${ }^{24,33,34}$ Hence, integrating an ANN with image texture combinations computed from a $0.5-\mathrm{m}$ WorldView-2 pan-sharpened image would be effective in detecting G. scutellatus induced vegetation defoliation. The WorldView-2 pan-sharpened dataset was selected because of its high spatial resolution, thus providing enhanced image texture information for detecting vegetation defoliation.

Although image texture has shown potential in detecting vegetation defoliation in the past, surprisingly its capabilities have not been fully explored. Therefore, the aim of this study was 
to explore the ability of image texture combinations computed from a $0.5-\mathrm{m}$ WorldView-2 pan-sharpened image for detecting and mapping G. scutellatus induced vegetation defoliation using an ANN. More specifically, we investigated the performance of (1) image texture in various processing combinations, (2) spectral reflectance in various processing combinations, and finally, (3) image texture combinations versus spectral reflectance combinations in detecting G. scutellatus induced vegetation defoliation.

\section{Methods}

\subsection{Study Area}

The study was conducted in the Sappi Hodgsons Estate (30'59'85'E; 29'19'03”'S), near Greytown in KwaZulu-Natal, South Africa (Fig. 1). This area covers 6391 ha of land and falls under the midlands mistbelt grassland bioregion. The landscape is undulating with an elevation ranging from 1030 to $1590 \mathrm{~m}$ above sea level. The area is characterized by summer rainfall ranging from 730 to $1280 \mathrm{~mm} /$ annum, with summer temperatures ranging from $24^{\circ} \mathrm{C}$ to the mid$30 \mathrm{~s}$. Winter months are dominated by misty conditions with temperatures ranging from $5^{\circ} \mathrm{C}$ to $14^{\circ} \mathrm{C}$. Apedal and plinthic soil forms are predominantly found in this region and are derived primarily from the Ecca group. The three principal genera dominated in this area are pine (P. patula, P. echinata), eucalyptus (E. grandis, E. dunnii), and black wattle (A. mearnsii). Frequency of G. scutellatus outbreaks commonly occur in this area during the South African spring and summer months.

\subsection{Imagery}

A WorldView-2 pan-sharpened image was obtained on September 20, 2012 under cloudless conditions. Figure 2 displays the characteristics ${ }^{35}$ of each WorldView-2 pan-sharpened band used in this study.

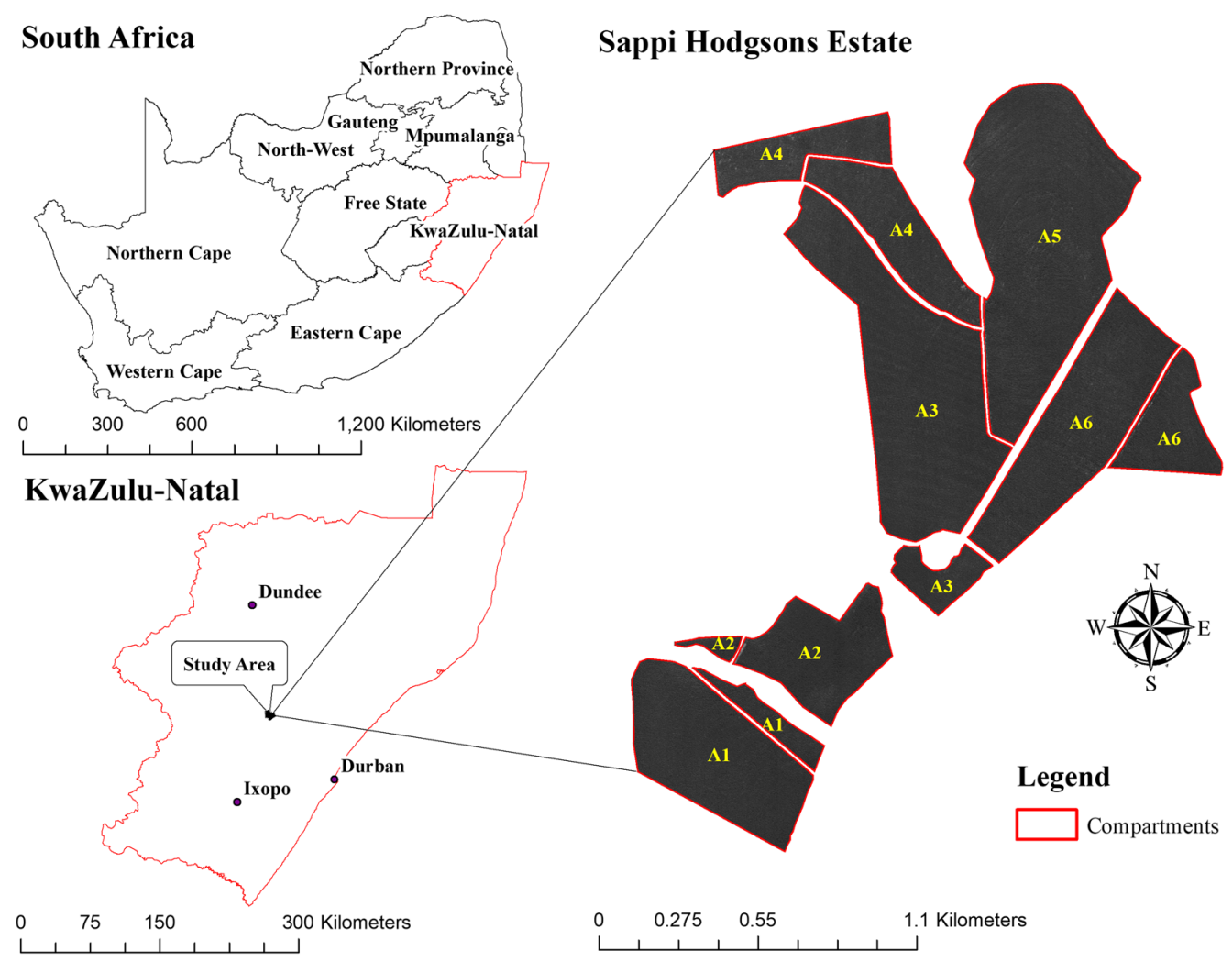

Fig. 1 Sappi Hodgsons Estate in KwaZulu-Natal, South Africa. Compartments are displayed using the WorldView-2 red band. 
Lottering et al.: Detecting and mapping Gonipterus scutellatus induced vegetation defoliation...

\begin{tabular}{|c|c|c|c|c|}
\hline Band & Range (nm) & Resolution (m) & Description & Image \\
\hline Coastal blue & $400-450$ & 0.5 & $\begin{array}{l}\text { Radiation in this region is absorbed by } \\
\text { chlorophyll in healthy vegetation, thus } \\
\text { aiding in vegetation analysis. }\end{array}$ & \\
\hline Blue & $450-510$ & 0.5 & $\begin{array}{l}\text { Chlorophyll absorbs radiation in this } \\
\text { region, playing an essential role in } \\
\text { analysing vegetation. }\end{array}$ & \\
\hline Green & $510-580$ & 0.5 & $\begin{array}{l}\text { Measures vegetation vigour by focusing on } \\
\text { peak reflectance in this region. }\end{array}$ & \\
\hline Yellow & $585-625$ & 0.5 & $\begin{array}{l}\text { This region is important for classifying } \\
\text { features on the earth's surface. }\end{array}$ & \\
\hline Red & $630-690$ & 0.5 & $\begin{array}{l}\text { Vegetation is effectively discriminated in } \\
\text { this region. }\end{array}$ & \\
\hline Red edge & $705-745$ & 0.5 & $\begin{array}{l}\text { This region is effective in measuring } \\
\text { vegetation health and vegetation } \\
\text { classification. }\end{array}$ & \\
\hline Near-IR1 & $770-895$ & 0.5 & $\begin{array}{l}\text { This region assists in vegetation } \\
\text { discrimination. }\end{array}$ & \\
\hline Near-IR2 & $860-1040$ & 0.5 & $\begin{array}{l}\text { This region allows for broader vegetation } \\
\text { analysis. }\end{array}$ & \\
\hline
\end{tabular}

Fig. 2 Characteristics of the WorldView-2 pan-sharpened spectral bands.

The image was atmospherically calibrated to the top-of-atmosphere reflectance using fast line-of-sight atmospheric analysis of spectral hypercube radiative transfer algorithm in ENVI $4.7^{36}$ and was georectified and orthorectified using 25 well-distributed ground control points. Following georectification, a root mean square error (RMSE) of less than one pixel size $(0.5 \mathrm{~m})$ was obtained. The image was then projected to Universal Transverse Mercator projection and the World Geodetic System 84 datum.

\subsection{Field Data Collection}

Field data were collected between September 24, 2012 to October 5, 2012, which commenced 4 days after the acquisition of the WorldView-2 pan-sharpened image and coincided with G. scutellatus induced vegetation defoliation being at a peak. The Hawths tool in ArcGIS 10.3 was used to randomly generate $30 \times 30 \mathrm{~m}$ plots over the study area using an existing WorldView-2 image. Prior field surveys that were conducted within the plantation showed that the $30 \times 30 \mathrm{~m}$ plots were adequate for detecting levels of vegetation defoliation induced by the weevil. These plots were at least $15 \mathrm{~m}$ away from other features, such as roads, and were located in field using a handheld Trimble Geo-Explorer with submeter accuracy. Once the area of interest was located, a $30 \times 30 \mathrm{~m}$ plot was created in field and the percentage level of defoliation was established per plot. All trees within the $30 \times 30 \mathrm{~m}$ plot were inspected for $G$. scutellatus induced vegetation defoliation and was validated by an entomologist from Sappi forests. Defoliation levels were calculated as a percentage of defoliated trees to the total number of trees within the $30 \times 30 \mathrm{~m}$ plot. These estimates were then grouped into four major defoliation classes regularly used in forest inventories: $25 \%$ and less defoliation (low), $26 \%$ to $50 \%$ defoliation (medium), $51 \%$ to $75 \%$ defoliation (high), and greater than $75 \%$ defoliation (severe). Training areas were created using these $30 \times 30 \mathrm{~m}$ plots overlaid 
Table 1 Summary of collected field data.

\begin{tabular}{|c|c|c|c|c|c|c|c|c|}
\hline Class & \multicolumn{2}{|c|}{$1 \%$ to $25 \%$} & \multicolumn{2}{|c|}{$26 \%$ to $50 \%$} & \multicolumn{2}{|c|}{$51 \%$ to $75 \%$} & \multicolumn{2}{|r|}{$>75 \%$} \\
\hline \multirow[t]{2}{*}{ No. of Plots } & & 65 & & 88 & & 89 & & 78 \\
\hline & Mean & $\begin{array}{l}\text { Standard } \\
\text { deviation }\end{array}$ & Mean & $\begin{array}{l}\text { Standard } \\
\text { deviation }\end{array}$ & Mean & $\begin{array}{l}\text { Standard } \\
\text { deviation }\end{array}$ & Mean & $\begin{array}{l}\text { Standard } \\
\text { deviation }\end{array}$ \\
\hline Defoliation (\%) & 15.58 & 6.73 & 36.81 & 6.95 & 60.55 & 6.68 & 81.32 & 6.33 \\
\hline
\end{tabular}

onto the texture and spectral images. This resulted in a total of 320 sample plots showing different levels of percentage defoliation. A summary of the field data collected is presented in Table 1.

\subsection{Image Texture}

Image texture is a function of local variance within an image and is dependent on the properties of a neighborhood of pixels. ${ }^{24,37}$ It is a useful approach for detecting vegetation defoliation, because vegetation structural changes induced by defoliation result in image texture variation. $^{22}$ In addition, several studies have illustrated the superiority of image texture as a source of information, particularly with high spatial resolution imagery. ${ }^{24,26}$ These are divided into two categories, namely the gray-level occurrence matrix (GLOM) and the gray-level co-occurrence matrix (GLCM). GLOM ignores the spatial relationship between pixels and is computed from the histogram of pixel intensities within a window. ${ }^{38}$ Figure 3 provides a brief description of GLOM image texture parameters.

\begin{tabular}{|c|c|c|c|}
\hline Parameter & Formula & Description & E.g. NIR $1(3 \times 3)$ \\
\hline Data range & $\begin{array}{c}\max \{X\}-\min \{X\} \\
\text { Where } X=x_{1}, x_{2}, \ldots, x_{\mathrm{k}}\end{array}$ & $\begin{array}{l}\text { Calculates the pixel data } \\
\text { range [38]. }\end{array}$ & \\
\hline Entropy & $\begin{array}{l}\sum_{i=0}^{N-1} p(i) \log _{2}[p(i)] \\
\text { Where } N \text { is the total number of } \\
\text { intensity levels }\end{array}$ & $\begin{array}{l}\text { Measures histogram } \\
\text { uniformity [39]. }\end{array}$ & \\
\hline Mean & $A V G=\frac{\sum_{k} X_{k}}{K}$ & $\begin{array}{l}\text { Determines the mean } \\
\text { texture value at each plot } \\
{[38] .}\end{array}$ & \\
\hline Skewness & $\begin{array}{l}\qquad \mu_{3}=\sigma^{-3} \sum_{1=0}^{N-1}(i-\mu)^{3} p(i) \\
\text { Where } N \text { is the total number intensity } \\
\text { levels }\end{array}$ & $\begin{array}{l}\text { Measures the skewness of } \\
\text { the dataset [39]. }\end{array}$ & \\
\hline Variance & $\begin{array}{l}\qquad \frac{\sum\left(x_{i j}-M\right)^{2}}{n-1} \\
\text { Where } x_{i j} \text { is the digital number of the } \\
\text { pixel }(i, j) \text {, and } n \text { is the number of } \\
\text { pixels in the moving window }\end{array}$ & $\begin{array}{l}\text { Accounts for the } \\
\text { variability of the spectral } \\
\text { response of pixels [39]. }\end{array}$ & \\
\hline
\end{tabular}

Fig. 3 First-order (GLOM) image texture parameters. ${ }^{38,39}$ 
On the other hand, GLCM determines the possibility of all pairwise combinations of graylevels within a window. ${ }^{24,25}$ When determining the GLCM, a set of gray-level co-occurrence probabilities are stored, and statistics are then applied to the matrix to generate image texture parameters. ${ }^{40}$ Figure 4 provides a brief description of GLCM image texture parameters.

In this study, the two categories of image texture were selected to determine their potential in detecting weevil-induced vegetation defoliation and were computed from a $0.5-\mathrm{m}$ WorldView-2 pan-sharpened image with a co-occurrence shift of $x=1, y=1$ and $\theta=45 \mathrm{deg}$. The angle has minimal influence on the coefficient of determination ${ }^{41}$ and therefore using this angle exclusively was deemed adequate to calculate image texture parameters. The window sizes used for each image texture parameter computed was based on a study conducted by Lottering and Mutanga. ${ }^{2}$ They used the minimal variance to determine optimal spatial resolutions for detecting levels of

\begin{tabular}{|c|c|c|c|}
\hline Parameter & Formula & Description & E.g. NIR $1(3 \times 3)$ \\
\hline Contrast & $\sum_{i, j=0}^{N-1} P_{i, j}(i-j)^{2}$ & $\begin{array}{l}\text { Determines the overall } \\
\text { local variation within a } \\
\text { window [30]. }\end{array}$ & \\
\hline Correlation & $\left.\sum_{i, j=0}^{N-1} P_{i, j} \frac{\left(i-\mu_{i}\right)\left(i-\mu_{j}\right)}{\sqrt{\left(\sigma_{i}^{2}\right)\left(\left(\sigma_{j}^{2}\right)\right.}}\right]$ & $\begin{array}{l}\text { Calculates the gray-level } \\
\text { linear-dependency within } \\
\text { an image [41]. }\end{array}$ & \\
\hline Dissimilarity & $\sum_{i, j=0}^{N-1} P_{i, j}|i-j|$ & $\begin{array}{l}\text { Measures local variation } \\
\text { within an image [42]. }\end{array}$ & \\
\hline Entropy & $\sum_{i, j=0}^{N-1} P_{i, j}\left(-\ln P_{i, j}\right)$ & $\begin{array}{l}\text { A statistical measure of } \\
\text { uncertainty [30]. }\end{array}$ & \\
\hline Homogeneity & $\sum_{i, j=0}^{N-1} \frac{P_{i, j}}{1+(i-j)^{2}}$ & $\begin{array}{l}\text { Determines smoothness of } \\
\text { image texture [43]. }\end{array}$ & \\
\hline Mean & $\begin{aligned} \mu_{i} & =\sum_{\substack{i, j=0 \\
N-1}}^{N-1} i\left(P_{i, j}\right) \\
\mu_{j} & =\sum_{i, j=0} j\left(P_{i, j}\right)\end{aligned}$ & $\begin{array}{l}\text { Mean gray-level in the } \\
\text { small neighbourhood [39]. }\end{array}$ & \\
\hline Second Moment & $\sum_{i, j=0}^{N-1} P_{i, j^{2}}$ & $\begin{array}{l}\text { Is an indicator of local } \\
\text { homogeneity [30]. }\end{array}$ & \\
\hline Variance & $\begin{aligned} \sigma_{i}^{2} & =\sum_{i, j=0}^{N-1} P_{i, j}\left(i-\mu_{i}\right)^{2} \\
\sigma_{j}^{2} & =\sum_{i, j=0}^{N-1} P_{i, j}\left(i-\mu_{j}\right)^{2}\end{aligned}$ & $\begin{array}{l}\text { Variability of the spectral } \\
\text { response of pixels [39]. }\end{array}$ & \\
\hline
\end{tabular}

Fig. 4 Second-order (GLCM) image texture parameters. ${ }^{30,39,41-43}$ 
G. scutellatus induced vegetation defoliation. The study concluded that an optimal spatial resolution for low and medium levels of defoliation was established at $2.5 \mathrm{~m}(5 \times 5)$, and for high and severe levels of defoliation, an optimal spatial resolution was established at $3.5 \mathrm{~m}(7 \times 7)$ and $4.5 \mathrm{~m}(9 \times 9)$, respectively. Therefore, in this study, we computed image texture parameters using moving window sizes in accordance with the optimal spatial resolutions at which levels of defoliation were best represented. The mean values of each of the samples were then extracted in ArcGIS 10.3 and corresponded with all 320 sample plots. These image texture parameters were computed using ENVI 4.7 software.

\subsection{Processing the WorldView-2 Pan-Sharpened Image for Modeling}

\subsubsection{WorldView-2 pan-sharpened image was processed in two steps}

- Step 1: Single spectral bands, two-band spectral combination, and three-band spectral combination

This step involves testing the spectral reflectance of single bands and band combinations of the WorldView-2 pan-sharpened image in detecting weevil induced vegetation defoliation. Using the optimal spatial resolutions established by Lottering and Mutanga, ${ }^{2}$ the $0.5-\mathrm{m}$ WorldView-2 pan-sharpened image was resampled accordingly. These spectral processing combinations were then formulated in the following manner:

1) The spectral reflectance of the 8 WorldView-2 pan-sharpened bands were used in an ANN.

2) All possible combinations of any 2 spectral reflectance bands were used in an ANN. These combinations were derived using Eq. (1):

$$
\frac{\mathrm{B} 1-\mathrm{B} 2}{\mathrm{~B} 1+\mathrm{B} 2}
$$

where B1 and B2 are spectral reflectance bands or image texture parameters.

3) All possible combinations of any three spectral reflectance bands were used in an ANN. These combinations were derived using Eq. (2):

$$
\frac{\mathrm{B} 1-\mathrm{B} 2}{\mathrm{~B} 1+\mathrm{B} 3}
$$

where B1, B2, and B3 are spectral reflectance bands or image texture parameters.

- Step 2: Single image texture bands, two-band image texture combination, and three-band image texture combination

Thirteen image texture parameters were computed from each of the eight WorldView-2 pan-sharpened bands. Window sizes were selected based on the optimal spatial resolution established by Lottering and Mutanga. ${ }^{2}$ These image texture parameters were then formulated in the following manner:

1) Single image texture bands were computed from each of the eight WorldView-2 pan-sharpened bands and were used in an ANN.

2) All possible combinations of any two image texture parameters were used in an ANN. These combinations were derived using Eq. (1).

3) All possible combinations of any three image texture parameters were used in an ANN. These combinations were derived using Eq. (2).

\subsection{Artificial Neural Network Analysis}

This study used an ANN to determine the relationship between spectral reflectance and image texture parameters with $G$. scutellatus induced vegetation defoliation. Figure 5 illustrates the structure of an ANN.

Each model was trained using a backpropagation algorithm with one hidden layer. ${ }^{24,34}$ This supervised approach makes use of the gradient descent technique that aims to decrease 


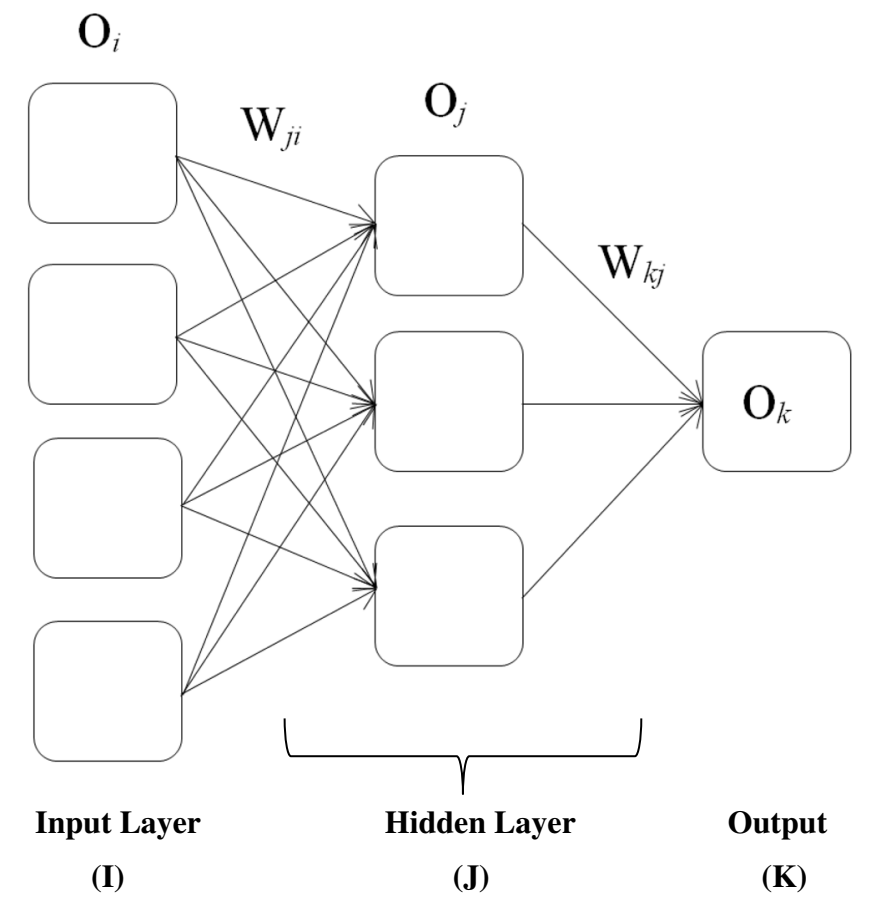

Fig. 5 Representation of a feedforward neural network, where $O_{i}$ represents the layer comprising the spectral reflectance or texture parameters, $O_{j}$ represents the hidden layer to which $O_{i}$ and $O_{k}$ are connected, $O_{k}$ represents the output layer, $W_{j i}$ and $W_{k j}$ represent the weight value. ${ }^{34}$

the prediction of error. The algorithm functions in a forward and backward phase. The forward phase introduces the spectral or image texture parameters to the network. The model is subsequently run with initial random weights that generate an output for each of the inputs. ${ }^{44}$ In the hidden node, the product of the input and initial weight is summed up to produce a $Z_{j}$ value for the $j^{\prime}$ th layer. ${ }^{45}$ Equation (3) illustrates this as follows:

$$
Z_{j}=\sum_{J} W_{j i} \times O_{i}
$$

A neural network having three layers namely; $i, j, k$, and the $k$ layer being the output, $S_{k}$ can be calculated as follows:

$$
S_{k}=\sum_{j} W_{k j} Z_{j}
$$

where $S_{k}$ is the value from the hidden layer $j$ and $W_{k j}$ is the weight value.

An aspect on nonlinearity is added to the network when the $Z_{j}$ passes through a sigmoidal activation function. ${ }^{45}$ The output is defined as follows:

$$
O_{j}=\frac{1}{1+e^{-\left(Z_{j}+\theta\right) / \theta_{0}}},
$$

where $\theta$ is a threshold and $\theta_{0}$ is a constant.

Once the output values for each node are calculated, the forward phase stops. This is followed by the backward phase, where changes in the predicted and observed RMSE are directed back to the network to decrease overall error. This phase reoccurs until the error is at a minimum.

In the current study, the dataset (320 plots) was randomly divided into test (96 plots) and training (224 plots) data, using a repeated hold out sample with 100 iterations. The optimal number of nodes was established by manually changing the number of nodes in the hidden layer. Training epochs were set at 5000, this was done to avoid over training the model. ${ }^{24}$ The learning rate and momentum of the model were set at 0.01 and 0.30 , respectively. 


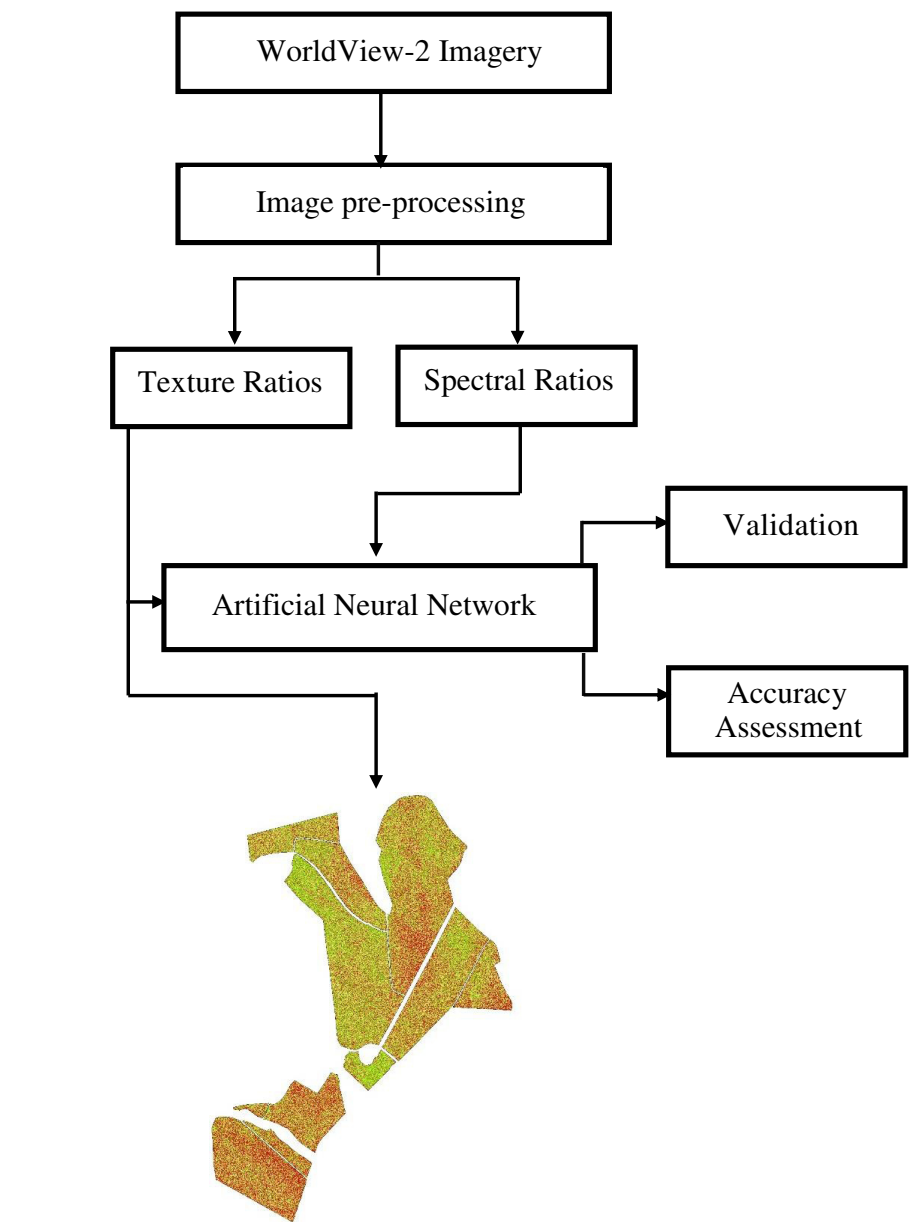

Map depicting the spatial distribution of weevil induced vegetation defoliation

Fig. 6 Flowchart showing the research methodology.

\subsection{Accuracy Assessment}

Model performance of the spectral and image texture models was based on an independent test (96 plots) dataset. Each model's performance was tested using the coefficient of determination $\left(R^{2}\right)$, RMSE, and \%RMSE between observed and predicted levels of G. scutellatus induced vegetation defoliation. Models with the highest $R^{2}$, lowest RMSE, and \%RMSE were retained for detecting vegetation defoliation. Figure 6 shows a flowchart of the methodology undertaken to achieve the objectives of this study.

\section{Results}

Figure 7 illustrates the difference in $\%$ defoliation over the study area. From a total of 320 plots, $20.31 \%$ were scored low ( $1 \%$ to $25 \%$ ), $27.50 \%$ were scored medium (26\% to $50 \%$ ), $27.81 \%$ were scored high $(51 \%$ to $75 \%$ ), and $24.38 \%$ were scored severe $(>75 \%)$ for visual estimates of percentage defoliation.

\subsection{Relationship Between Spectral Reflectance and Image Texture Parameters with Weevil Induced Vegetation Defoliation}

The relationship between each parameter and defoliation was determined using a Pearson's correlation test. Image texture and spectral parameters used in model development subsequently underwent a sequential forward selection. This allowed for the selection of the best spectral 
Lottering et al.: Detecting and mapping Gonipterus scutellatus induced vegetation defoliation...

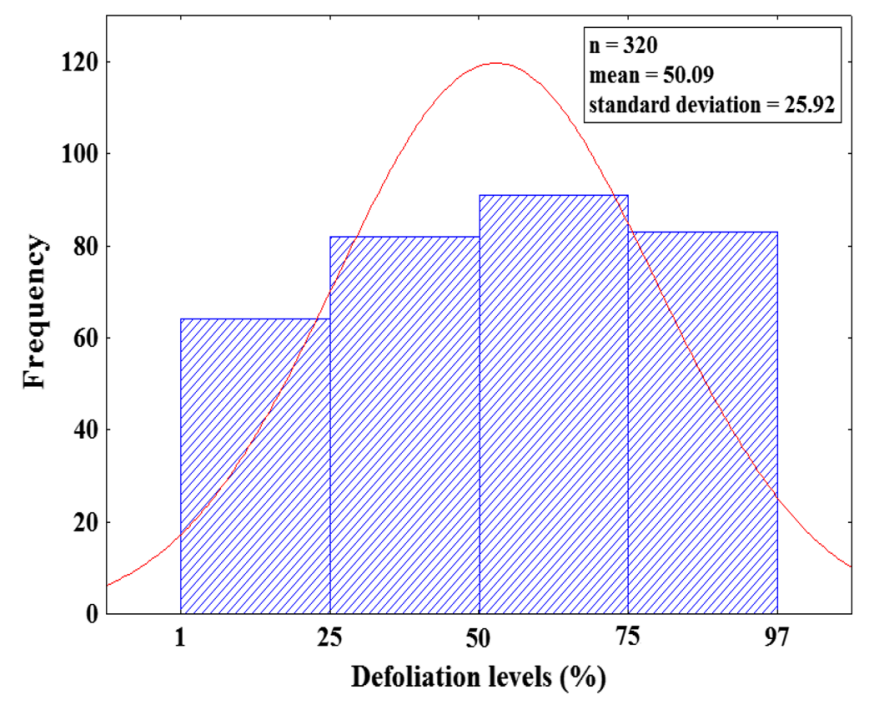

Fig. 7 Histogram illustrating defoliation levels within the study area.

reflectance and image texture parameters for the development of models to detect weevilinduced vegetation defoliation.

\subsection{Selected Spectral Reflectance and Image Texture Parameters for the Artifical Neural Network}

Since the three-band image texture combination and three-band spectral reflectance combination models showed the highest correlation with vegetation defoliation in their respective groups, we chose to illustrate these two models in Table 2. Table 2 also shows the input variables selected by the sequential forward selection algorithm, which were subsequently used in the ANN for model development. In addition, the Pearson's correlation test revealed that all selected parameters from each model were highly correlated with weevil-induced vegetation defoliation, however higher correlations were established using the three-band image texture combination model. It can also be noted that image texture parameters selected for development of the three-band image texture combination model were predominantly gray-level co-occurrence image texture parameters computed primarily from the red, red edge, near-infrared 1, and near-infrared 2 bands.

\subsection{Artificial Neural Networks}

Using an ANN, we detected G. scutellatus induced vegetation defoliation using spectral and image texture parameters computed from a $0.5-\mathrm{m}$ WorldView-2 pan-sharpened image. We achieved this by changing the number of nodes in the hidden layer. A list of parameters used to train each model are shown in Tables 3 and 4 for spectral and image texture models, respectively.

Table 2 Significant $(p<0.01)$ combinations of spectral and image texture variables for detecting defoliation.

\begin{tabular}{|c|c|c|c|c|}
\hline \multirow{2}{*}{$\frac{\text { Variable }}{\text { Defoliation }}$} & \multicolumn{2}{|c|}{ Three-band spectral reflectance } & \multicolumn{2}{|c|}{ Three-band texture parameters } \\
\hline & Spectral band & $r$ & Texture & $r$ \\
\hline & $\frac{(\text { RED) }-(\text { NIR } 1)}{(\text { RED })+(\text { RED EDGE })}$ & -0.67 & $\frac{(\mathrm{B} 8, \mathrm{E}, 9, \mathrm{C})-(\mathrm{B} 5, \mathrm{H}, 5, \mathrm{C})}{(\mathrm{B} 8, \mathrm{E}, 9, \mathrm{C})+(\mathrm{B} 6, \mathrm{Cr}, 5, \mathrm{C})}$ & -0.70 \\
\hline & $\frac{(\text { NIR2)-(RED) }}{\text { (NIR2)+(RED EDGE) }}$ & 0.69 & $\frac{(\mathrm{B} 6, \mathrm{H}, \mathrm{T}, \mathrm{C})-(\mathrm{B} 7, \mathrm{~S}, 5, \mathrm{C})}{(\mathrm{B} 6, \mathrm{H}, \mathrm{7}, \mathrm{C})+(\mathrm{B} 8, \mathrm{~S}, 5, \mathrm{C})}$ & -0.74 \\
\hline & $\frac{(\text { NIR } 1)-(\text { REDEDGE })}{\text { (NIR1)+(RED) }}$ & -0.71 & $\frac{(\mathrm{B} 7, \mathrm{H}, 5, \mathrm{C})-(\mathrm{B} 8, \mathrm{Cr}, \mathrm{9}, \mathrm{C})}{(\mathrm{B} 7, \mathrm{H}, 5, \mathrm{C})+(\mathrm{B} 5, \mathrm{H}, \mathrm{7}, \mathrm{C})}$ & 0.73 \\
\hline & $\frac{(\text { RED EDGE)-(RED) }}{\text { (REDEDGE)+(NIR2) }}$ & 0.72 & $\frac{(\mathrm{B} 5, \mathrm{H}, 5, \mathrm{C})-(\mathrm{B} 8, \mathrm{E}, 9,)}{(\mathrm{B} 5, \mathrm{H}, 5, \mathrm{C})+(\mathrm{B} 7, \mathrm{Cr}, 9, \mathrm{C})}$ & -0.74 \\
\hline
\end{tabular}


Lottering et al.: Detecting and mapping Gonipterus scutellatus induced vegetation defoliation...

Table 3 Best trained ANN parameters for detecting levels of defoliation using spectral reflectance data.

\begin{tabular}{lccc}
\hline \hline Model & Input & Hidden & Profile \\
\hline Single spectral bands & 5 & 4 & MLP 5:5-4-1:1 \\
Two-band spectral combination & 5 & 4 & MLP 5:5-4-1:1 \\
Three-band spectral combination & 4 & 3 & MLP 4:4-3-1:1 \\
\hline \hline
\end{tabular}

Table 4 Best trained ANN parameters for detecting levels of defoliation using image texture.

\begin{tabular}{lccc}
\hline \hline Model & Input & Hidden & Profile \\
\hline Single texture bands & 5 & 3 & MLP 5:5-3-1:1 \\
Two-band texture combination & 4 & 3 & MLP 4:4-3-1:1 \\
Three-band texture combination & 4 & 2 & MLP 4:4-2-1:1 \\
\hline \hline
\end{tabular}

\subsection{Training, Testing and Applying the Artificial Neural Network to Detect Levels Vegetation Defoliation}

Each of the models were trained using the parameters displayed in Tables 3 and 4. Using random initial weights, each model was run a maximum of five times. ${ }^{24,44}$ Weight configurations that yielded the highest $R^{2}$, lowest RMSE, and \%RMSE between predicted and measured defoliation based on an independent test dataset were reserved for detecting vegetation defoliation.

\subsection{Performance of Spectral and Image Texture ANN Models}

Table 5 shows that the three-band spectral reflectance combination model $\left[R^{2}=0.80\right.$ and RMSE $=1.35$ (2.59\% of the mean measured defoliation)] outperformed both the two-band spectral reflectance combination $\left[R^{2}=0.74\right.$ and $\mathrm{RMSE}=1.48(2.83 \%$ of the mean measured defoliation)] and single spectral reflectance band $\left[R^{2}=0.60\right.$ and RMSE $=1.79(3.43 \%$ of the mean measured defoliation)] models. This was due to a higher $R^{2}$, lower RMSE, and \%RMSE value based on an independent test dataset.

While ANN models using the single image texture bands $\left[R^{2}=0.82\right.$ and $\mathrm{RMSE}=0.95$ (1.82\% of the mean measured defoliation)] and two-band image texture combinations $\left[R^{2}=0.85\right.$ and $\mathrm{RMSE}=1.05$ (2.01\% of the mean measured defoliation) $]$ yielded high $R^{2}$ values in detecting vegetation defoliation, Table 6 shows the ANN model using the three-band image texture combination $\left[R^{2}=0.90\right.$ and $\mathrm{RMSE}=0.85(1.63 \%$ of the mean measured defoliation $\left.)\right]$ yielded the highest $R^{2}$, lowest RMSE, and \%RMSE value based on an independent test dataset.

Table 5 Comparison between spectral reflectance predictive models $(n=320)$.

\begin{tabular}{|c|c|c|c|c|c|c|c|}
\hline \multicolumn{2}{|l|}{ Variable } & \multicolumn{2}{|c|}{ Single spectral bands } & \multicolumn{2}{|c|}{$\begin{array}{l}\text { Two-band spectral } \\
\text { model }\end{array}$} & \multicolumn{2}{|c|}{$\begin{array}{l}\text { Three-band spectral } \\
\text { model }\end{array}$} \\
\hline Defoliation & Data & $R^{2}$ & RMSE & $R^{2}$ & RMSE & $R^{2}$ & RMSE \\
\hline & Test & 0.60 & $1.79(3.43 \%)$ & 0.74 & $1.48(2.83 \%)$ & 0.80 & $1.35(2.59 \%)$ \\
\hline & Train & 0.58 & $1.32(2.52 \%)$ & 0.72 & $0.93(1.78 \%)$ & 0.79 & $0.89(1.71 \%)$ \\
\hline
\end{tabular}

Note: $R^{2}$ : All significant at $p<0.01$ 
Lottering et al.: Detecting and mapping Gonipterus scutellatus induced vegetation defoliation...

Table 6 Comparison between image texture predictive models $(n=320)$.

\begin{tabular}{|c|c|c|c|c|c|c|c|}
\hline \multicolumn{2}{|l|}{ Variable } & \multicolumn{2}{|c|}{$\begin{array}{l}\text { Single texture } \\
\text { parameters }\end{array}$} & \multicolumn{2}{|c|}{$\begin{array}{l}\text { Two-band texture } \\
\text { model }\end{array}$} & \multicolumn{2}{|c|}{$\begin{array}{l}\text { Three-band texture } \\
\text { model }\end{array}$} \\
\hline Defoliation & Data & $R^{2}$ & RMSE & $R^{2}$ & RMSE & $R^{2}$ & RMSE \\
\hline & Test & 0.82 & $0.95(1.82 \%)$ & 0.85 & $1.05(2.01 \%)$ & 0.90 & $0.85(1.63 \%)$ \\
\hline & Train & 0.81 & $0.83(1.59 \%)$ & 0.86 & $0.70(1.34 \%)$ & 0.88 & $0.61(1.17 \%)$ \\
\hline
\end{tabular}

Note: $R^{2}$ : All significant at $p<0.01$

\subsection{Testing and Applying the ANN to Detect Weevil Defoliation Using Local Binary Patterns}

Local binary patterns (LBPs) are an alternate texture analysis proposed by Ojala et al. ${ }^{46}$ LBPs were computed from the WorldView-2 pan-sharpened image using the same moving window sizes used to compute the image texture and combination models. Similarly, the resulting LBPs were also used to develop models using a backpropagation ANN to detect levels of vegetation defoliation. The model that yielded the highest $R^{2}$, lowest RMSE, and \%RMSE was retained and used for detecting vegetation defoliation induced by the weevil. Table 7 shows the results obtained from the LBP model.

\subsection{Comparing the Performance of Image Texture Models and the LBP Model}

Tables 6 and 7 show the results of the image texture models and LBP model, respectively. Based on independent test datasets, all image texture models yielded higher $R^{2}$ values for detecting defoliation induced by the weevil when compared to the LBP model. In addition, all image texture models also yielded lower RMSE and \%RMSE results when compared to the LBP model, based on independent test datasets.

\subsection{Mapping the Distribution of G. Scutellatus Vegetation Defoliation Using an ANN}

Although all three image texture models yielded high correlation coefficients, a predictive map showing the distribution of defoliation was developed using the best trained three-band image texture combination model. This was due to the superior performance of this model in detecting G. scutellatus induced vegetation defoliation over all tested models. The predicted map was developed using R statistical software. Figure 8 shows the distribution of levels of G. scutellatus induced vegetation defoliation over the study area.

\subsection{Sensitivity Analysis}

Since the three-band image texture combination model outperformed all the models in detecting vegetation defoliation, we tested the importance of the selected variables in this model. A sensitivity analysis was run to determine which variables played the most prominent role

Table 7 Results obtained using the LBP model $(n=320)$.

\begin{tabular}{lcc}
\hline \hline \multirow{2}{*}{ Variable } & \multicolumn{2}{c}{ LBP model } \\
\cline { 3 - 3 } Defoliation & $R^{2}$ & RMSE \\
\hline & 0.78 & $1.11(2.13 \%)$ \\
& 0.77 & $1.08(2.07 \%)$ \\
\hline \hline
\end{tabular}

Note: $R^{2}$ : All significant at $p<0.01$ 


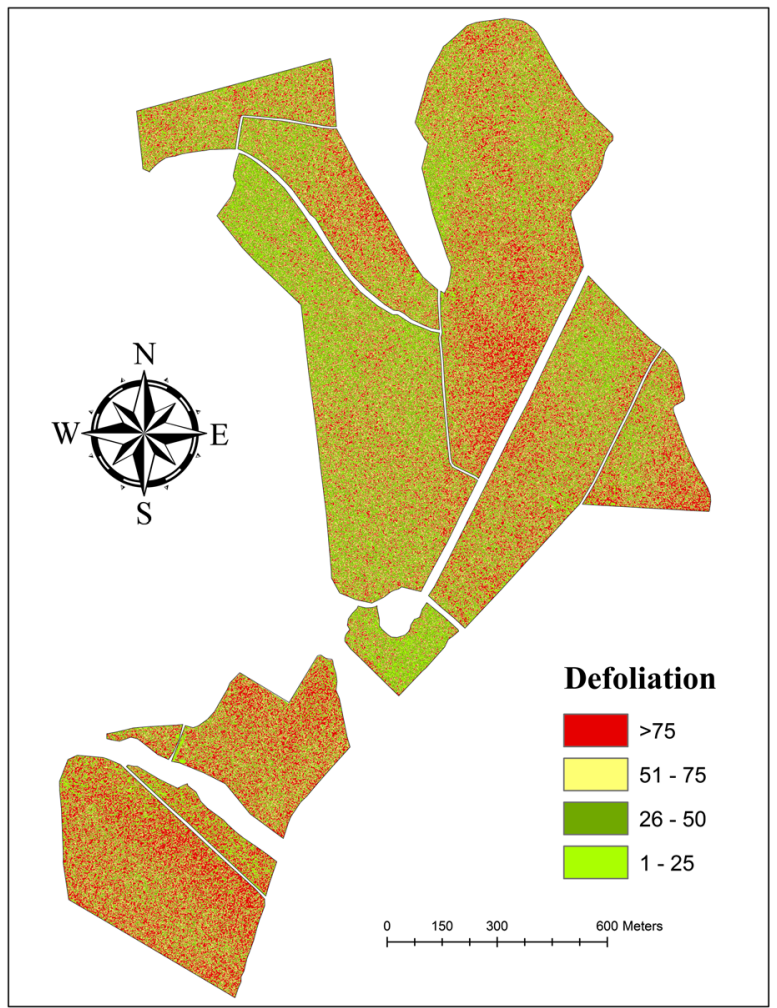

Fig. 8 Predictive map showing the distribution of G. scutellatus over the entire study area.

Table 8 Sensitivity analysis of the three-band image texture combination model used in the ANN.

\begin{tabular}{|c|c|c|c|}
\hline Variable & Rank & Image texture combination & Ratio \\
\hline \multirow[t]{4}{*}{ Defoliation } & 1 & $\frac{(\mathrm{B} 6, \mathrm{H}, 7, \mathrm{C})-(\mathrm{B} 7, \mathrm{~S}, 5, \mathrm{C})}{(\mathrm{B} 6, \mathrm{H}, 7, \mathrm{C})+(\mathrm{B} 8, \mathrm{~S}, 5, \mathrm{C})}$ & 1.94 \\
\hline & 2 & $\frac{(\mathrm{B} 7, \mathrm{H}, 5, \mathrm{C})-(\mathrm{B} 8, \mathrm{Cr}, 9, \mathrm{C})}{(\mathrm{B} 7, \mathrm{H}, 5, \mathrm{C})+(\mathrm{B}, \mathrm{H}, \mathrm{7}, \mathrm{C})}$ & 1.25 \\
\hline & 3 & $\frac{(\mathrm{B} 5, \mathrm{H}, 5, \mathrm{C})-(\mathrm{B} 8, \mathrm{E}, 9, \mathrm{C})}{(\mathrm{B} 5, \mathrm{H}, \mathrm{S}, \mathrm{C})+(\mathrm{B} 7, \mathrm{Cr}, \mathrm{,}, \mathrm{C})}$ & 1.09 \\
\hline & 4 & $\frac{(\mathrm{B} 8, \mathrm{E}, 9, \mathrm{C})-(\mathrm{B} 5, \mathrm{H}, 5, \mathrm{C})}{(\mathrm{B} 8, \mathrm{E}, \mathrm{9}, \mathrm{C})+(\mathrm{B} 6, \mathrm{Cr}, 5, \mathrm{C})}$ & 1.05 \\
\hline
\end{tabular}

Note: B5, B6, B7, B8: red, red edge, near-IR1, near-IR2; H: homogeneity; E: entropy; Cr: correlation; S: second moment; C: co-occurrence; 5, 7, 9: $5 \times 5,7 \times 7,9 \times 9$

in developing the three-band image texture combination model. Input variables with higher ratios show more importance than lower ratio variables in model development. Table 8 shows a sensitivity analysis for the three-band image texture combination model.

Values within the ratio column are calculated for each image texture combination as if the variable is absent during network execution. The error obtained in the absence of the variable is divided by the error obtained when the variable is present. An index with higher ratios would illustrate a reduction in network performance if removed from the network.

\section{Discussion}

\subsection{Relationship Between Image Texture Combinations and Vegetation Defoliation}

Although several studies have reported on the ability of image texture in detecting vegetation defoliation, ${ }^{22,30}$ the current study, however, was the first to report on the ability of image 
texture combinations in detecting vegetation defoliation. This study introduced a three-band image texture combination approach in an attempt to improve the detection of vegetation defoliation. Overall, the results in this study showed that image texture combinations have the capacity to adequately detect and map vegetation defoliation, outperforming traditional spectral reflectance data. Among the seven models tested, the three-band image texture combination showed the highest overall accuracy $\left[R^{2}=0.90\right.$ and RMSE $=0.85$ (1.63\% of the mean measured defoliation)] in detecting vegetation defoliation. Conversely, using single spectral reflectance bands produced the lowest overall accuracy $\left[R^{2}=0.60\right.$ and RMSE $=1.79(3.43 \%$ of the mean measured defoliation) $]$. This was followed by the two-band spectral reflectance combination model, which produced a somewhat better result $\left[R^{2}=0.74\right.$ and RMSE $=1.48$ ( $2.83 \%$ of the mean measured defoliation) $]$. However, the threeband spectral reflectance combination produced the highest overall accuracy of the three spectral reflectance models $\left[R^{2}=0.80\right.$ and $\mathrm{RMSE}=1.35(2.59 \%$ of the mean measured defoliation)].

The detection of G. scutellatus induced vegetation defoliation improved immensely using image texture. This result is consistent with the findings of many studies that reported improved performance of image texture over spectral reflectance data. ${ }^{22,24,37}$ For example, Nichol and Sarker ${ }^{37}$ found that image texture outperformed spectral reflectance data in estimating vegetation biomass. In the current study, this improvement was noted in all three image texture models. The results obtained from each image texture model were very promising with the single image texture parameter model having an $R^{2}$ of 0.82 and an RMSE of 0.95 (1.82\% of the mean measured defoliation), which improved further using the two-band image texture combination model $\left[R^{2}=0.85\right.$ and RMSE $=1.05$ (2.01\% of the mean measured defoliation) $]$. However, the highest agreement was achieved using the three-band image texture combination model $\left[R^{2}=0.90\right.$ and RMSE $=0.85$ ( $1.63 \%$ of the mean measured defoliation)], a result that has not been previously reported in literature for detecting levels of pest-induced vegetation defoliation. This could be due to the high spatial resolution of the WorldView-2 pan-sharpened image. For instance, several studies have emphasized the dependence of image texture on the spatial resolution of remotely sensed data. ${ }^{22,24,26,27}$ In addition, the improved accuracy of the three-band image texture combination model could have also been attributed to the fact that the moving windows used to compute each image texture parameter matched the optimal spatial resolution at which each level of weevil-induced vegetation defoliation was best represented. Lottering and Mutanga, ${ }^{2}$ for example, found that optimizing the spatial resolution of remotely sensed data improved the detection of vegetation defoliation. This result was subsequently compared to the result obtained from the LBP model, whose performance was not as significant when compared to the image texture and texture combination models in detecting vegetation defoliation induced by the weevil. Similarly, Kaya et al. ${ }^{47}$ also found that gray-level co-occurrence image texture outperformed the LBPs in evaluating image texture features.

Moreover, it was also noted that image texture parameters selected for model development were predominately co-occurrence texture parameters when compared to the occurrence texture parameters. According to Rao et al. ${ }^{48}$ co-occurrence texture parameters are the most applicable for remote sensing of vegetation. This was echoed by previous studies that focused on forest structure and image texture. ${ }^{24,30,49}$ For example, Yuan et $\mathrm{al}^{30}$ found that co-occurrence texture parameters were better at detecting sugar maple decline when compared to occurrence texture parameters. In another study, Moskal and Franklin ${ }^{22}$ successfully detected aspen defoliation using homogeneity, which is a co-occurrence texture parameter. The sensitivity analysis in our study showed that homogeneity appeared in most processing combinations, thus reaffirming the significance of co-occurrence texture parameters in detecting vegetation defoliation. Furthermore, image texture parameters computed from the red, red edge, near-infrared 1, and near-infrared 2 bands of the WorldView-2 pan-sharpened image were predominately selected for developing the three-band image texture combination model. Similarly, structurally relevant information found in the red, red edge, and NIR spectral ranges have also confirmed the results of other studies focusing on forest structure, for example, Xu et al. ${ }^{50}$ Ingram et al. ${ }^{33}$ Cho et al., ${ }^{51}$ and Gebreslasie et al. ${ }^{52}$ All three moving windows seemed to play an equal role in the development of the three-band image texture combination model, which was probably due to the 
moving window sizes corresponding with the optimal spatial resolution best representing specific levels of weevil-induced vegetation defoliation.

\subsection{Spatial Distribution of Defoliation Levels Over the Study Area}

The results have shown that the three-band image texture combination model has the ability to effectively detect and map levels of vegetation defoliation induced by the weevil G. scutellatus. From the predictive map, it can be seen that in all compartments, there was some degree of defoliation. However, higher and severe levels of defoliation were more prominent toward the southern parts of the map. The rational explanation behind this could be due to preference shown by the weevil. Several studies have highlighted the selective nature of G. scutellatus, whereby certain eucalyptus species are more preferred than others. ${ }^{53-56}$ For example, Fuentes et al. ${ }^{56}$ found that Eucalyptus camaldulensis was more susceptible to G. scutellatus defoliation than Eucalyptus robusta or Eucalyptus globulus. In our case, the eucalyptus species found toward the southern parts of the predictive map were Eucalyptus grandis and toward the northern parts were Eucalyptus dunni. Therefore, the more preferred Eucalyptus grandis may have been initially consumed followed by the less preferred Eucalyptus dunni.

To summarize, all image texture models produced very promising results, however, the threeband image texture combination model was the more superior of the models. This was primarily due to the high spatial resolution of the WorldView-2 pan-sharpened image and the unique threeband image texture processing combination technique, which combines the advantages of both image texture and band combinations. The methodology conducted in this study could be applied to other areas, provided the remotely sensed image is optimized to specific spatial resolutions at which levels of defoliation are best represented. Furthermore, it is also essential to use high spatial resolution data for improved detection outcomes, as image texture is scale dependent. ${ }^{22,24,27}$

\section{Conclusion}

Although the potential of image texture has been previously demonstrated, no study has investigated the full potential of image texture in detecting and mapping G. scutellatus induced vegetation defoliation. This study has therefore shown an integrated approach in detecting weevil-induced vegetation defoliation using image texture combinations and an ANN. This study has revealed that:

- the three-band image texture combination model showed the highest overall accuracy in detecting vegetation defoliation, when compared to the two-band image texture combination model and the single-band image texture model,

- the three-band spectral reflectance combination model showed the highest overall accuracy in detecting vegetation defoliation, when compared to the two-band spectral reflectance combination model and the single-band spectral reflectance model,

- and finally, all image texture models outperformed all spectral reflectance models in detecting G. scutellatus induced vegetation defoliation.

Overall, this study was the first attempt to detect vegetation defoliation using image texture combinations and an ANN. Detecting vegetation defoliation with high spatial resolution imagery and image texture combinations can be a reliable practical alternative to conventional field surveys. The three-band image texture combination proposed in this study is an objective, quantitative, and a cost effective means of detecting vegetation defoliation. The result is important in improving the overall accuracy of detecting and mapping pest-induced vegetation defoliation.

\section{Acknowledgments}

The authors of this paper would like to acknowledge the support of the University of KwaZuluNatal, Applied Centre for Climate and Earth System Science (ACCESS), Sappi Forests, and the National Research Foundation of South Africa (Grant No. 114898), which allowed for the successful completion of this research. 


\section{References}

1. S. Gebeyehu, B. P. Hurley, and M. J. Wingfield, "A new lepidopteran insect pest discovered on commercially grown Eucalyptus nitens in South Africa," S. Afr. J. Sci. 101(1/2), 26-28 (2005).

2. R. Lottering and O. Mutanga, "Optimising the spatial resolution of WorldView-2 pan-sharpened imagery for predicting levels of Gonipterus scutellatus defoliation in KwaZulu-Natal, South Africa," ISPRS J. Photogramm. Remote Sens. 112, 13-22 (2016).

3. S. W. Newete, R. G. Oberprieler, and M. J. Byrne, "The host range of the Eucalyptus weevil, Gonipterus "scutellatus" Gyllenhal (Coleoptera: Curculionidae), in South Africa," Ann. For. Sci. 68(5), 1005-1013 (2011).

4. F. G. C. Tooke, "The eucalyptus snout-beetle, Gonipterus scutellatus Gyll: a study of its ecology and control by biological means," Ent. Mem. Dept. Agric. U. S. Afr. 3, 1-282 (1955).

5. C. W. Mally, "The eucalyptus snout beetle (Gonipterus scutellatus Gyll.)," J. Dept. Agric. S. Afr. 9, 415-442 (1924).

6. A. D. Loch and M. Matsuki, "Effects of defoliation by Eucalyptus weevil, Gonipterus scutellatus, and chrysomelid beetles on growth of Eucalyptus globulus in southwestern Australia," For. Ecol. Manage. 260(8), 1324-1332 (2010).

7. A. Cheraghian, "Eucalyptus weevil Gonipterus scutellatus Gyllenhal 1833 Coleoptera: Curculionidae," 1-234 (2013).

8. K. F. Richardson and R. H. Meakins, "Inter- and intra- specific variation in the susceptibility of eucalypts to the snout beetle Gonipterus scutellatus Gyll. (Coleoptera: Curculionidae)," S. Afr. For. J. 139(1), 21-31 (1986).

9. A. R. Reis et al., "Efficiency of biological control of Gonipterus platensis (Coleoptera: Curculionidae) by Anaphes nitens (Hymenoptera: Mymaridae) in cold areas of the Iberian Peninsula: implications for defoliation and wood production in Eucalyptus globules," For. Ecol. Manage. 270(0), 216-222 (2012).

10. G. D. Tribe, "The present status of Anaphes nitens (Hymenoptera: Mymaridae), an egg parasitoid of the Eucalyptus snout beetle Gonipterus scutellatus, in the Western Cape Province of South Africa," Southern Afr. For. J. 203(1), 49-54 (2005).

11. A. D. Loch and R. B. Floyd, "Insect pests of Tasmanian blue gum, Eucalyptus globulus globulus, in south-western Australia: history, current perspectives and future prospects," Austral Ecol. 26(5), 458-466 (2001).

12. J. T. Huber and G. L. Prinsloo, "Redescription of Anaphes nitens (girault) and description of two new species of Anaphes haliday (hymenoptera: mymaridae), parasites of Gonipterus scutellatus gyllenhal (coleoptera: curculionidae) in Tasmania," Aust. J. Entomol. 29(4), 333-341 (1990).

13. R. Ismail, O. Mutanga, and A. Ahmed, "Discriminating Sirex noctilio attack in pine forest plantations in South Africa using high spectral resolution data, in Hyperspectral Remote Sensing of Tropical and Sub-Tropical Forests, M. Kalacska and G. Arturo SanchezAzofeifa, Eds., CRC Press, Florida, pp. 161-175 (2008).

14. Z. Oumar, O. Mutanga, and R. Ismail, "Predicting Thaumastocoris peregrinus damage using narrow band normalized indices and hyperspectral indices using field spectra resampled to the hyperion sensor," Int. J. Appl. Earth Obs. Geoinf. 21(0), 113-121 (2013).

15. K. M. de Beurs and P. A. Townsend, "Estimating the effect of gypsy moth defoliation using MODIS," Remote Sens. Environ. 112(10), 3983-3990 (2008).

16. L. Eklundh, T. Johansson, and S. Solberg, "Mapping insect defoliation in scots pine with MODIS time-series data," Remote Sens. Environ. 113(7), 1566-1573 (2009).

17. R. Ismail, O. Mutanga, and U. Bob, "Forest health and vitality: the detection and monitoring of Pinus patula trees infected by Sirex noctilio using digital multispectral imagery," S. Hemisphere For. J. 69(1), 39-47 (2007).

18. Z. Oumar and O. Mutanga, "Using WorldView-2 bands and indices to predict bronze bug (Thaumastocoris peregrinus) damage in plantation forests," Int. J. Remote Sens. 34(6), 2236-2249 (2012). 
Lottering et al.: Detecting and mapping Gonipterus scutellatus induced vegetation defoliation...

19. R. Lottering, O. Mutanga, and K. Peerbhay, "Detecting and mapping levels of Gonipterus scutellatus-induced vegetation defoliation and leaf area index using spatially optimized vegetation indices," Geocarto Int. 33(3), 277-292 (2018).

20. S. E. Franklin, H. Fan, and X. Guo, "Relationship between Landsat TM and SPOT vegetation indices and cumulative spruce budworm defoliation," Int. J. Remote Sens. 29(4), 1215-1220 (2007).

21. J. P. Spruce et al., "Assessment of MODIS NDVI time series data products for detecting forest defoliation by gypsy moth outbreaks," Remote Sens. Environ. 115(2), 427-437 (2011).

22. L. M. Moskal and S. E. Franklin, "Relationship between airborne multispectral image texture and aspen defoliation," Int. J. Remote Sens. 25(14), 2701-2711 (2004).

23. S. E. Franklin et al., "Aerial and satellite sensor detection and classification of western spruce budworm defoliation in a subalpine forest," Can. J. Remote Sens. 21(3), 299-308 (1995).

24. R. Lottering and O. Mutanga, "Estimating the road edge effect on adjacent Eucalyptus grandis forests in KwaZulu-Natal, South Africa, using texture measures and an artificial neural network," J. Spatial Sci. 57(2), 153-173 (2012).

25. R. M. Haralick, K. Shanmugam, and I. H. Dinstein, "Textural features for image classification," IEEE Trans. Syst. Man Cybern. SMC-3(6), 610-621 (1973).

26. H. S. Dungey and B. M. Potts, "Eucalypt hybrid susceptibility to Gonipterus scutellatus (Coleoptera: Curculionidae)," Austral Ecol. 28(1), 70-74 (2003).

27. M. Wulder, "Optical remote-sensing techniques for the assessment of forest inventory and biophysical parameters," Prog. Phys. Geogr. 22(4), 449-476 (1998).

28. S. E. Franklin, W. W. Bowers, and G. Ghitter, "Discrimination of adelgid-damage on single balsam fir trees with aerial remote sensing data," Int. J. Remote Sens. 16(15), 2779-2794 (1995).

29. S. E. Franklin, M. A. Wulder, and G. R. Gerylo, "Texture analysis of IKONOS panchromatic data for Douglas-fir forest age class separability in British Columbia," Int. J. Remote Sens. 22(13), 2627-2632 (2001).

30. X. Yuan, D. King, and J. Vlcek, "Sugar maple decline assessment based on spectral and textural analysis of multispectral aerial videography," Remote Sens. Environ. 37(1), 47-54 (1991).

31. R. B. Myneni and F.G. Hall, "The interpretation of spectral vegetation indexes," IEEE Trans. Geosci. Remote Sens. 33(2), 481-486 (1995).

32. W. Wang et al., "Estimating leaf nitrogen concentration with three-band vegetation indices in rice and wheat," Field Crops Res. 129, 90-98 (2012).

33. J. C. Ingram, T. P. Dawson, and R. J. Whittaker, "Mapping tropical forest structure in southeastern Madagascar using remote sensing and artificial neural networks," Remote Sens. Environ. 94(4), 491-507 (2005).

34. O. Mutanga and A. K. Skidmore, "Integrating imaging spectroscopy and neural networks to map grass quality in the Kruger National Park, South Africa," Remote Sens. Environ. 90(1), 104-115 (2004).

35. DigitalGlobe, The Benefits of the 8 Spectral Bands of WorldView-2, United States (2010).

36. ENVI, Version 4.7, Exelis Visual Information Solutions, ITT Industries, Boulder, Colorado (2009).

37. J. E. Nichol and M. L. R. Sarker, "Improved biomass estimation using the texture parameters of two high-resolution optical sensors," IEEE Trans. Geosci. Remote Sens. 49(3), 930-948 (2011).

38. V. St-Louis et al., "High-resolution image texture as a predictor of bird species richness," Remote Sens. Environ. 105(4), 299-312 (2006).

39. A. Materka and M. Strzelecki, "Texture analysis methods-a review," Technical University of Lodz, Institute of Electronics, COST B11 Report, Brussels, pp. 9-11 (1998).

40. R. Jobanputra and D. A. Clausi, "Preserving boundaries for image texture segmentation using grey level co-occurring probabilities," Pattern Recognit. 39(2), 234-245 (2006).

41. F. Kayitakire, C. Hamel, and P. Defourny, "Retrieving forest structure variables based on image texture analysis and IKONOS-2 imagery," Remote Sens. Environ. 102(3), 390-401 (2006). 
Lottering et al.: Detecting and mapping Gonipterus scutellatus induced vegetation defoliation...

42. Y. Rubner et al., "Empirical evaluation of dissimilarity measures for color and texture," Comput. Vision Image Understanding 84(1), 25-43 (2001).

43. E. M. Tuttle et al., "Using remote sensing image texture to study habitat use patterns: a case study using the polymorphic white-throated sparrow (Zonotrichia albicollis)," Global Ecol. Biogeogr. 15(4), 349-357 (2006).

44. Y. Zhang et al., "Application of an empirical neural network to surface water quality estimation in the Gulf of Finland using combined optical data and microwave data," Remote Sens. Environ. 81(2-3), 327-336 (2002).

45. A. Skidmore et al., "Performance of a neural network: mapping forests using GIS and remotely sensed data," Photogramm. Eng. Remote Sens. 63(5), 501-514 (1997).

46. T. Ojala, M. Pietikainen, and D. Harwood, "Performance evaluation of texture measures with classification based on Kullback discrimination of distributions," in Proc. 12th Int. Conf. Pattern Recognit. (1994).

47. Y. Kaya et al., "Evaluation of texture features for automatic detecting butterfly species using extreme learning machine," J. Exp. Theor. Artif. Intell. 26(2), 267-281 (2014).

48. P. V. N. Rao et al., "Textural analysis of IRSID panchromatic data for land cover classification," Int. J. Remote Sens. 23(17), 3327-3345 (2002).

49. S. E. Franklin et al., "Incorporating texture into classification of forest species composition from airborne multispectral images," Int. J. Remote Sens. 21(1), 61-79 (2000).

50. B. Xu, P. Gong, and R. Pu, "Crown closure estimation of oak savannah in a dry season with Landsat TM imagery: comparison of various indices through correlation analysis," Int. J. Remote Sens. 24(9), 1811-1822 (2003).

51. M. A. Cho, A. K. Skidmore, and I. Sobhan, "Mapping beech (Fagus sylvatica L.) forest structure with airborne hyperspectral imagery," Int. J. Appl. Earth Obs. Geoinf. 11(3), 201-211 (2009).

52. M. T. Gebreslasie, F. B. Ahmed, and J. A. N. van Aardt, "Extracting structural attributes from IKONOS imagery for Eucalyptus plantation forests in KwaZulu-Natal, South Africa, using image texture analysis and artificial neural networks," Int. J. Remote Sens. 32(22), 7677-7701 (2011).

53. A. R. Clarke, S. Paterson, and P. Pennington, "Gonipterus scutellatus Gyllenhal (Coleoptera: Curculionidae) oviposition on seven naturally co-occurring Eucalyptus species," For. Ecol. Manage. 110(1-3), 89-99 (1998).

54. F. G. C. Tooke, "The eucalyptus snout beetle Gonipterus scutellatus Gyll. A study of its ecology and control by biological means," Entomol. Memoir 3, 1-26 (1953).

55. A. D. Loch, "Parasitism of the Eucalyptus weevil, Gonipterus scutellatus Gyllenhal, by the egg parasitoid, Anaphes nitens Girault, in Eucalyptus globulus plantations in southwestern Australia," Biol. Control 47(1), 1-7 (2008).

56. H. A. Fuentes et al., "Susceptibility of eucalyptus species to Gonipterus scutellatus and electrophoretic profiles of adult marker proteins," Agrociencia 42(3), 327-334 (2008).

Romano Lottering received his master's degree in applied environmental science (cum laude) and a PhD in environmental science from the University of KwaZulu-Natal, Pietermaritzburg, South Africa. From 2011 to present, he is a lecturer and research scientist at the University of KwaZulu-Natal. His research focus is on the utility of remotely sensed data to detect and map pest-induced vegetation defoliation in commercial forest plantations.

Onisimo Mutanga is a professor at the University of KwaZulu-Natal, Pietermaritzburg, South Africa. His research focus is on ecological assessment and monitoring of vegetation patterns using GIS and remote sensing. His focus in recent years has been on the development of remote sensing techniques for mapping tropical vegetation quality and quantity in an attempt to understand wildlife feeding patterns and distribution. His emerging niche areas include mapping vegetation species, disease infestation on plantation forests and agricultural crops as well as the quantification of forest degradation and its impact on biodiversity.

Kabir Peerbhay received his master's degree in applied environmental science (cum laude) and $\mathrm{a} \mathrm{PhD}$ in environmental science from the University of KwaZulu-Natal, Pietermaritzburg, 
Lottering et al.: Detecting and mapping Gonipterus scutellatus induced vegetation defoliation...

South Africa. From 2015 to present, he is a senior research scientist at Institute for Commercial Forestry Research and was recently appointed research fellow at the University of KwaZuluNatal. His research focus is on using remote sensing to detect and map alien invasive plant species in commercial forest plantations.

Riyad Ismail received his master's degree in GIS (cum laude) and a $\mathrm{PhD}$ in remote sensing from the University of KwaZulu-Natal, Pietermaritzburg, South Africa. He is a principal research officer at Sappi forests and a research fellow at the University of KwaZulu-Natal. His research focus is on remote sensing of forest health and the utility of machine learning algorithms to maximize the benefits of spatial technology. 